\section{Fractal properties and simulation of micro-seismicity for seismic hazard analysis: a comparison of North Anatolian and San Andreas Fault Zones}

\author{
Naside Ozer, ${ }^{1}$ Savas Ceylan ${ }^{1,2}$ \\ 'Istanbul University, Engineering Faculty, \\ Department of Geophysical Engineering, \\ Turkey; ${ }^{2}$ University of Missouri, \\ Department of Geological Sciences, \\ Columbia, MO, USA
}

\section{Abstract}

We analyzed statistical properties of earthquakes in western Anatolia as well as the North Anatolian Fault Zone (NAFZ) in terms of spatio-temporal variations of fractal dimensions, p- and b-values. During statistically homogeneous periods characterized by closer fractal dimension values, we propose that occurrence of relatively larger shocks $(\mathrm{M}>=$ 5.0 ) is unlikely. Decreases in seismic activity in such intervals result in spatial b-value distributions that are primarily stable. Fractal dimensions decrease with time in proportion to increasing seismicity. Conversely, no spatiotemporal patterns were observed for p-value changes. In order to evaluate failure probabilities and simulate earthquake occurrence in the western NAFZ, we applied a modified version of the renormalization group method. Assuming an increase in small earthquakes is indicative of larger shocks, we apply the mentioned model to micro-seismic $(\mathrm{M}<=3.0)$ activity, and test our results using San Andreas Fault Zone (SAFZ) data. We propose that fractal dimension is a direct indicator of material heterogeneity and strength. Results from a model suggest simulated and observed earthquake occurrences are coherent, and may be used for seismic hazard estimation on creeping strike-slip fault zones.

\section{Introduction}

Fractals are self-similar and scale-invariant objects. Fractal analysis provides a good proxy for analysis of a system with uncharacteristic size (or scale). This approach requires that the number of objects exceeding a specified size have a power-law dependence on the size. ${ }^{1}$ The power of the mentioned relation, called fractal dimension (Equation 1), is used to define scale-invariant systems. Briefly, fractal dimen- sion indicates the extent of data scattering. Higher fractal dimension values show increased randomness, while the zero values imply a completely deterministic system.

$$
N_{i}=C / r_{i}^{D}
$$

where $\mathrm{Ni}$ is the number of objects with length (size) ri, $\mathrm{C}$ is the ratio constant and the exponent $\mathrm{D}$ represents fractal dimension. Fractal dimensions of any order can be found by using Equations 2 and $3.2,3$

$$
D_{q}=\frac{\log C_{q}(r)}{\log (\mathrm{r})}
$$

$$
C_{q}(r)=\left\{\frac{1}{N} \sum_{i=1}^{N}\left[\frac{1}{N} \sum_{j=1}^{N} H\left(r-\left|x_{i}-x_{j}\right|\right)\right]^{q-1}\right\}^{1 /(q-1)}
$$

In Equations 2 and 3, $\mathrm{C}_{\mathrm{q}}(\mathrm{r})$ is referred to as correlation function, $\mathrm{H}$ is the Heaviside Step Function, and $\mathrm{q}$ is the order of statistical moment. The source code used in this study is modified from Sarraille and Difalco, ${ }^{3}$ and implements the algorithm of Grassberger and Procaccia, ${ }^{2}$ and Liebovitch and Toth. ${ }^{4}$ In 2D systems such as earthquake epicenter distributions, fractal dimensions range from 0.0 to 2.0. Here, we use only the first three dimensions: $\mathrm{D}_{0}$, capacity dimension; $\mathrm{D}_{1}$, information dimension; and $\mathrm{D}_{2}$, correlation dimension. Among the most studied scaling parameters, Gutenberg and Richter ${ }^{5}$ 's b-value is defined as a semi-logarithmic relationship between cumulative earthquake occurrence and magnitude (Equation 4). The b-value is commonly accepted as 1.0 for global seismicity. ${ }^{6-8}$ However, on a regional scale, it may vary between 0.5 and $1.5^{9}$, or 0.8 and $1.2^{7}$. The bvalue may be constrained by and directly proportional to heterogeneity and crack distribution in the crust. ${ }^{10}$ According to Wyss ${ }^{11}$ and Scholz, ${ }^{12}$ regional stress and b-value are inversely proportional.

$$
\log (N)=a-b m
$$

$\mathrm{Aki}^{6}$ proved that the b-value is scale invariant and its relationship to generalized fractal dimension can be described as $\mathrm{D}=2 \mathrm{~b}$. Further development of $\mathrm{Aki}^{6}$ 's generalization reveals dependence of this linear relationship on magnitude: $D=3 b, D=2 b$, and $D=b$ for small, intermediate and large events, respectively. ${ }^{13}$ According to Sukmono et al., ${ }^{14}$ fractal dimensions follow a pattern closely related to fault friction, which drops with large earthquakes. Consistent results from micro-crack investigations ${ }^{15}$ indicate progressive stepwise decrease in fractal dimensions, hence b-value, with deformation propagation. Although fractal
Correspondence: Naside Ozer, Istanbul University, Engineering Faculty, Department of Geophysical Engineering, 34320, Istanbul, Turkey. E-mail: naside@istanbul.edu.tr

Key words: North Anatolian Fault Zone, San Andreas Fault Zone, fractal dimension, b-value, renormalization group method.

Acknowledgments: the present work was carried out in the framework of the project number of 585/14082006, UDP-817/06042007, BYP-1881 and T-1489/13082007 of the research funds of Istanbul University. We thank Dr. Bedri Alpar for his help in improving the manuscript and Dr. Yildiz Altinok for her support. We also thank Editor in Chief, Dr. Gerassimos Papadopoulos and anonymous reviewers for their helpful criticism.

Received for publication: 5 December 2011.

Revision received: 30 January 2012.

Accepted for publication: 1 February 2012.

This work is licensed under a Creative Commons Attribution NonCommercial 3.0 License (CC BYNC 3.0).

(C) Copyright N.Ozer and S. Ceylan, 2012

Licensee PAGEPress, Italy

Research in Geophysics 2012; 2:e1

doi:10.4081/rg.2012.el

dimensions have been shown to decrease prior to big earthquakes, simultaneous increases in b-value have been reported by Nakaya. ${ }^{16}$ According to Wang, ${ }^{17}$ b-value variations are dependent on dynamic frictional forces and plate velocities. Contrary to other authors, Wang ${ }^{17}$ suggests weak correlation between fractal dimension and b-value. Fractal dimension and b-value calculations obtained from shallow and deep earthquakes reveal that smaller differences between them are observed in relatively aseismic regions. ${ }^{18}$ Here, we apply spatio-temporal fractal analysis to epicenteral distribution of earthquakes in western Anatolia $\left(38.4^{\circ}-41.6^{\circ} \mathrm{N}, 25.2^{\circ}-32.1^{\circ} \mathrm{E}\right)$, identifying a coherent pattern. Furthermore, we modify and employ the model of Smalley et al. ${ }^{19}$ simulating micro-earthquake occurrence along western NAFZ and SAFZ.

\section{Materials and Methods}

This study used data from Bogazici University, Kandilli Observatory and Earthquake Research Institute (KOERI) collected from 1975 to March 2007, with a threshold magnitude of $\mathrm{Mc}=2.3$. Temporal window lengths range from 10 to 300 days, with a visually determined ideal length of 150 days and 
l)

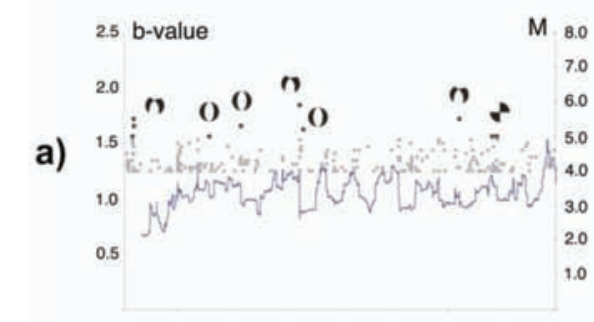

II)

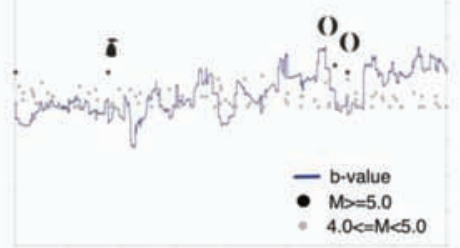

M
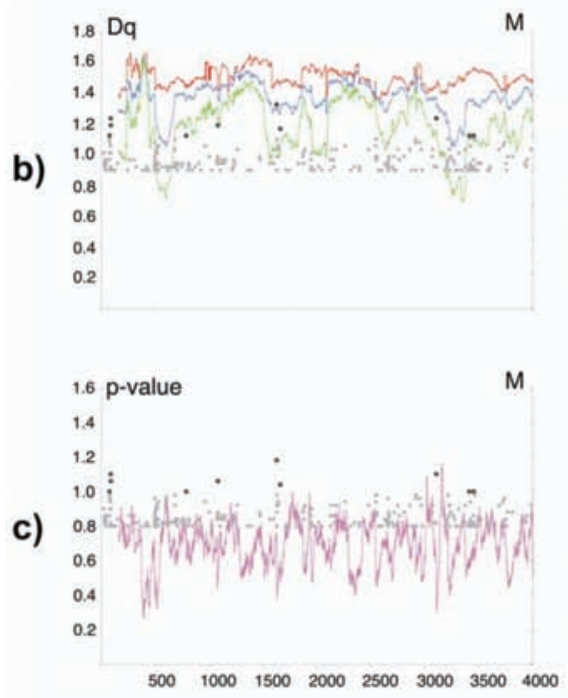
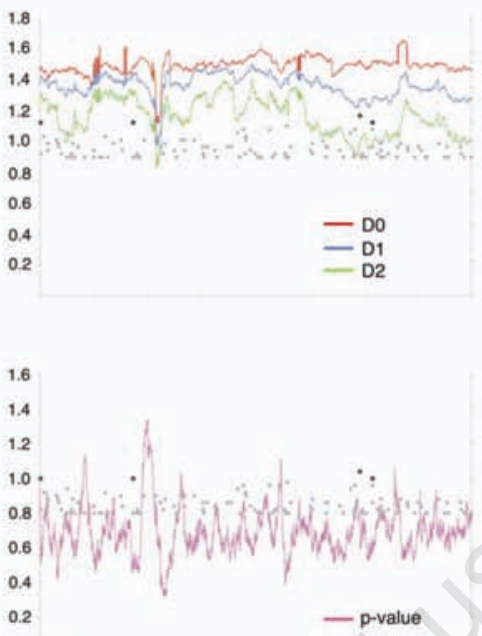

$40014500 \quad 5000 \quad 550060006500 \quad 7000 \quad 7500 \quad 8000$

Time (days)

Figure 1. Temporal changes of a) b-value, b) fractal dimensions, and c) p-value for western Anatolia. Columns delineate I) 0-4000, II) 4000-8000, III) 8000-12000 days. Focal mechanisms indicate general faulting types in regions with dense earthquake clustering of large shock occurrence. Solid black and gray dots denote earthquakes larger than $M>=5.0$ and $5.0>M>=4.0$, respectively. Data used is from KOERI with window length of 150 days.

window shifts of 0.5 days. Calculations were repeated using an earthquake occurrence of 450 , based on average number of events in ideal time windows. A grid scale of 0.3 by 0.3 degrees with shift of 0.1 degrees was used for spatial analysis. We used the least squares method to determine both $b$ - and p-values. The catalog completeness magnitude for NAFZ is visually determined as $\mathrm{M}=4.0$, using the magnitude-cumulative earthquake occurrence plot. All fractal dimensions are determined with the box counting algorithm. In order to avoid human error arising from digitization, complex geometry, or lack of other fault information, we preferred to use better-constrained earthquake loci for capacity dimension calculations, which is often related to fault distribution. In our simulated approach based on Smalley et al. ${ }^{19}$ we aimed to forecast microearthquake $(\mathrm{M}<=3.0)$ frequency for a given duration. Reference $\left(\mathrm{F}_{0}\right)$ and transferred stresses (F) are accounted for in the original model (Equation 5). This form of the equation is equivalent to Weibull distribution, widely used in fracture mechanics. ${ }^{8} \mathrm{~F} / \mathrm{F}_{0}=\mathrm{F}_{\mathrm{c}}=0.4807$ for threshold stress ratio gives the probability
III)
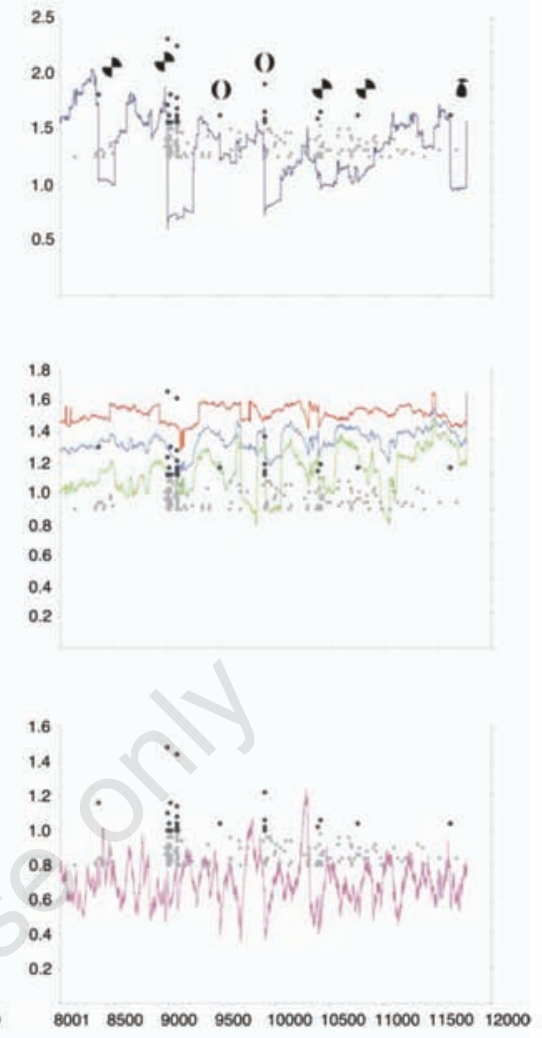
value of fracture $p c=0.2063$. Stresses applied to fault segments exceeding threshold probability result in fault failure, and consequently stress release, reducing the likelihood of further failure. During failure, stress release is simulated as stress transferred to adjacent segments. ${ }^{8}$

$$
\mathrm{p}_{0}(F)=1-\exp \left[-\left(\frac{F}{F_{0}}\right)^{2}\right]
$$

Our five-step modified version of the model of Smalley et al. ${ }^{19}$ begins with subdivision of fault zone into $\mathrm{dx}=0.08$ degrees one dimensional segments, incorporating both USGS and KOERI data. Segment length was determined by creating inter-event distance histogram for successive shocks. The upper magnitude limit for micro-earthquakes was chosen as 3.0. Following subdivision, segments are assigned strength values (s) according to Equation 6, where $D_{\text {uniform }}=2.0$ and $D_{0}$ is capacity dimension.

$$
s=\frac{D_{\text {uniform }}-D_{0}}{D_{\text {uniform }}}
$$

Threshold probabilities $\left(\mathrm{p}_{\mathrm{c}}\right)$ for each segment are calculated using Equation 7, where $\mathrm{F}_{\mathrm{c}}$ denotes threshold stress ratio of $0.4807 .{ }^{8}$

$$
p_{c}=1-\exp \left(-F_{c} s^{2}\right)
$$

A reference stress accumulated over 150 years is assumed. In this case, for each time interval ( $\mathrm{dT}=0.5$ days) $\mathrm{dF}=\mathrm{F}$.dT. After strength values are set, the first catalog earthquake is assigned to the corresponding segment. The stress in failed segment is distributed along adjacent segments until failure probability is lowered below the default threshold value. At each time step, we apply tectonic stresses and repeat calculations until the end of duration. Finally, we renormalize simulated number of earthquakes according to their correlation with observations. Our model is based on the assumptions of one earthquake occurrence per each time interval, and material homogeneity of fault segments.

\section{Results}

Closer fractal dimensions are referred to as statistically homogeneous (monofractals), while increasing dimension differences define statistical heterogeneity. Analysis of both event and time window temporal fractal dimensions demonstrate that statistically homogeneous periods are characterized by a lack of large earthquakes $(M>=5.0)$. Following such periods, as the fractal dimension differ- ences increase, larger events occur more frequently. Repeated calculations focused only on western NAFZ using different window length are consistent. However, comparison between this observed pattern and faulting types revealed no apparent relation (Figure 1). Although, no b- and p-value anomalies are observed, b-values show a broader scale trend (Figure 2). Regions of spatially concentrated seismic activity are positively correlated with fractal dimensions (Figure 3). This correlation is quantitatively expressed as $\ln [\ln (\mathrm{N})]=\alpha \exp$ (Dq) $( \pm 0.11)$, where $\mathrm{N}$ is the number of earthquakes, $\mathrm{Dq}$ is fractal dimension of any order, and $\alpha$ being the ratio constant. For western Anatolia, the constant $\alpha$ is $0.59,0.67$, and 0.68 for the statistical moment order $q=0,1,2$, respectively (Figures 4, 5). Moreover, larger earthquakes tend to be associated with regions having the globally accepted b-value of 1.01 ( \pm 0.01 ), and are less common in areas with b-values outside this range.

The relation between fractal distribution and seismicity is further supported by our modeling results. After renormalization, observed and simulated seismicity are coherent for microearthquakes, as quantitively expressed by the following equations

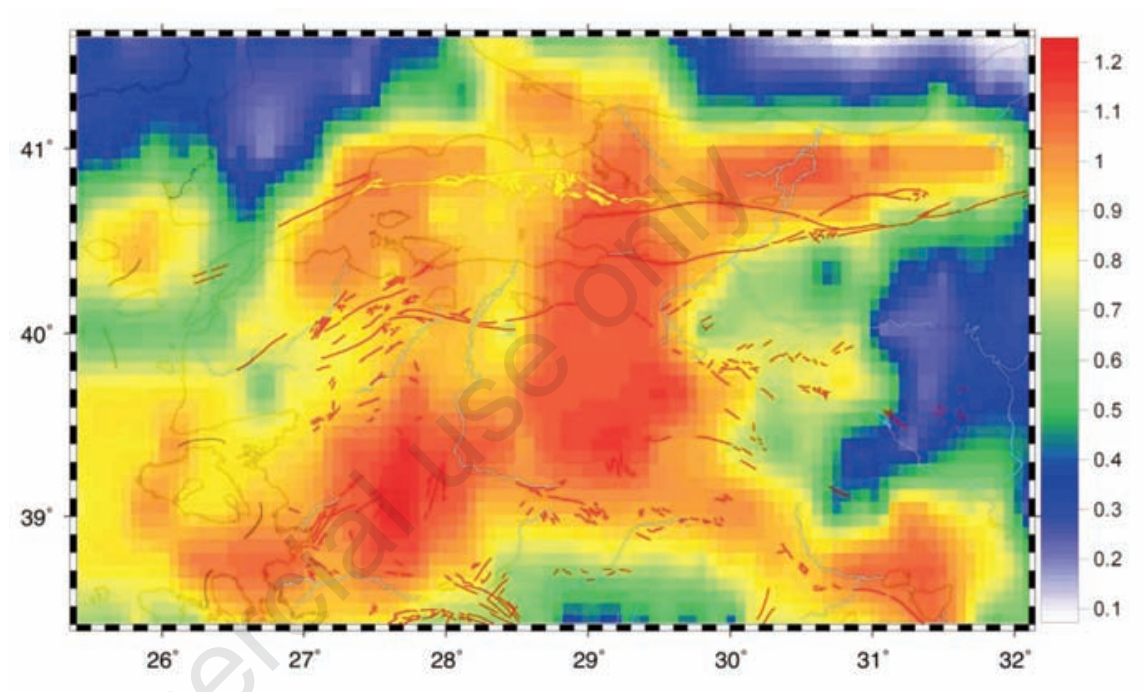

Figure 3. Spatial variation of capacity dimension for western Anatolia. Fault data was obtained from Şaroğlu et al., ${ }^{20}$ Barka $^{21}$ and Le Pichon et al. ${ }^{22}$ Map is prepared using Wessel and Smith. ${ }^{23}$

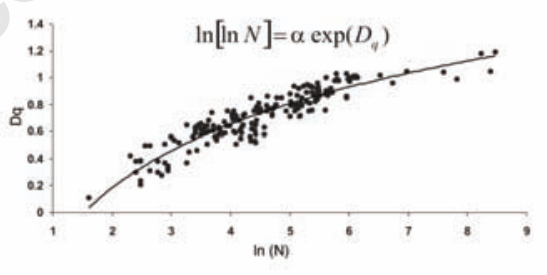

Figure 4. The relationship between number of dimensions and fractal dimensions in space.

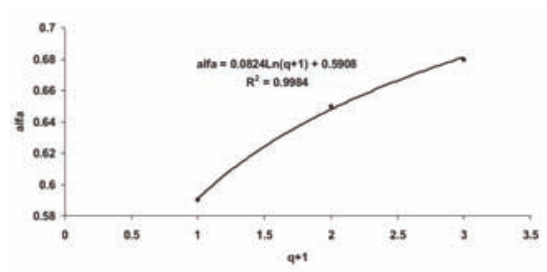

Figure 5. The relationship between order of statistical moment (q) and ratio coefficient (alfa).
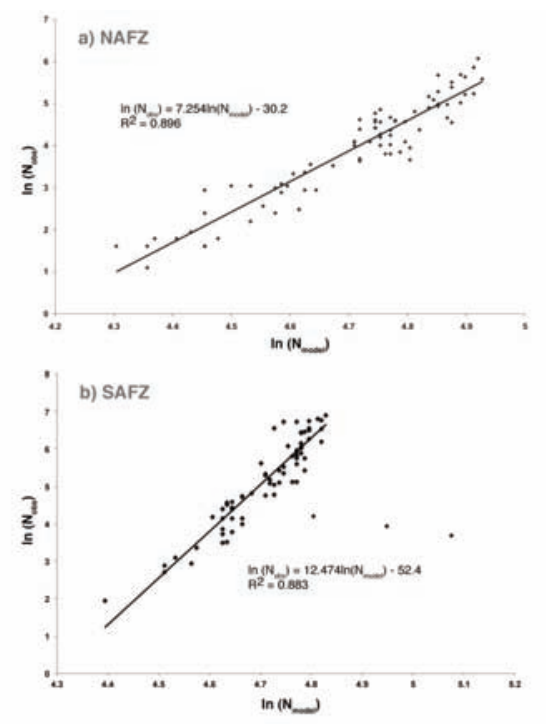

Figure 6. The relationship between modeled and observed number of earthquakes for a) western NAFZ and b) SAFZ. 
$\ln \left(N_{\text {obs }}\right)=7.254 \ln \left(N_{\text {mode }}\right)-30.2 \quad\left(R^{2}=0.896\right)$ for western NAFZ and $\ln \left(N_{o b s}\right)=12.474 \ln \left(N_{\text {mode }}\right)$ $52.4\left(R^{2}=0.883\right)$ for SAFZ (Figures 6, 7 and 8). Considering an input of just one actual event, the consistency between model results and observation is remarkable.

\section{Discussion}

Globally, $\mathrm{b}=1.0$ is commonly accepted as the normal value. ${ }^{6-8}$ For western Anatolia, we obtain $b=1.01( \pm 0.01)$ consistent with prior works. The significance level between our bvalue calculations is 0.065 , as implied by the Utsu test. ${ }^{24}$ Variations from the normal value in temporal scale may be caused by an increase in either material heterogeneity ${ }^{10}$ or stress level. ${ }^{11,12}$ Over geological time scales, such rapid alteration of heterogeneity is unlikely. Therefore, observed b-value variations are more probably a result of stress accumulation. Conversely, as earthquakes have no implications for broad stress change, we presume spatial variations to be attributed to pri- marily heterogeneity. The pattern observed in b-value changes over time (Figure 2) and follows three stages: i) oscillations from $\sim 0.2$ to 0.8 ; ii) exponential increase up to $\sim 2.0$, raising seismic hazard; followed by iii) stepwise decrease. Assuming cyclical behavior in bvalue variations, oscillations around mean value of 0.5 imply that western Marmara region is experiencing the initial stage. The observed temporal fractal pattern (Figure 1) suggests that the region is continually critically stressed, in accordance with the findings of Scholz ${ }^{25}$ and Rundle et al. ${ }^{26}$ and is reminiscent

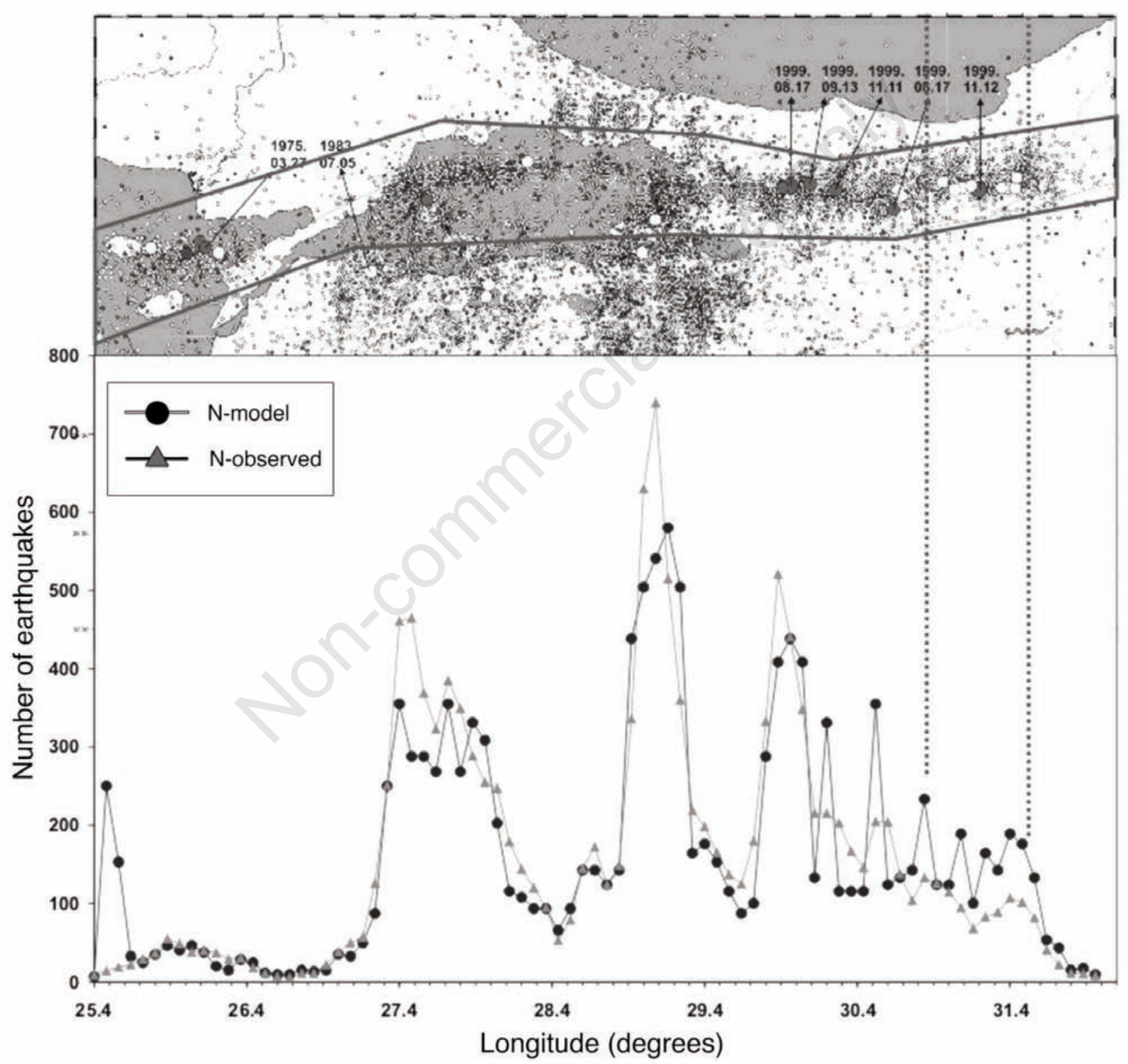

Figure 7. Modeled (solid black circles) and observed (triangles) earthquakes plotted against longitude. Seismicity in the study region is depicted (top). Western NAFZ is delineated by the polygon shown in the map (solid dark gray lines). Dashed lines outline the boundaries of proposed asperity. 


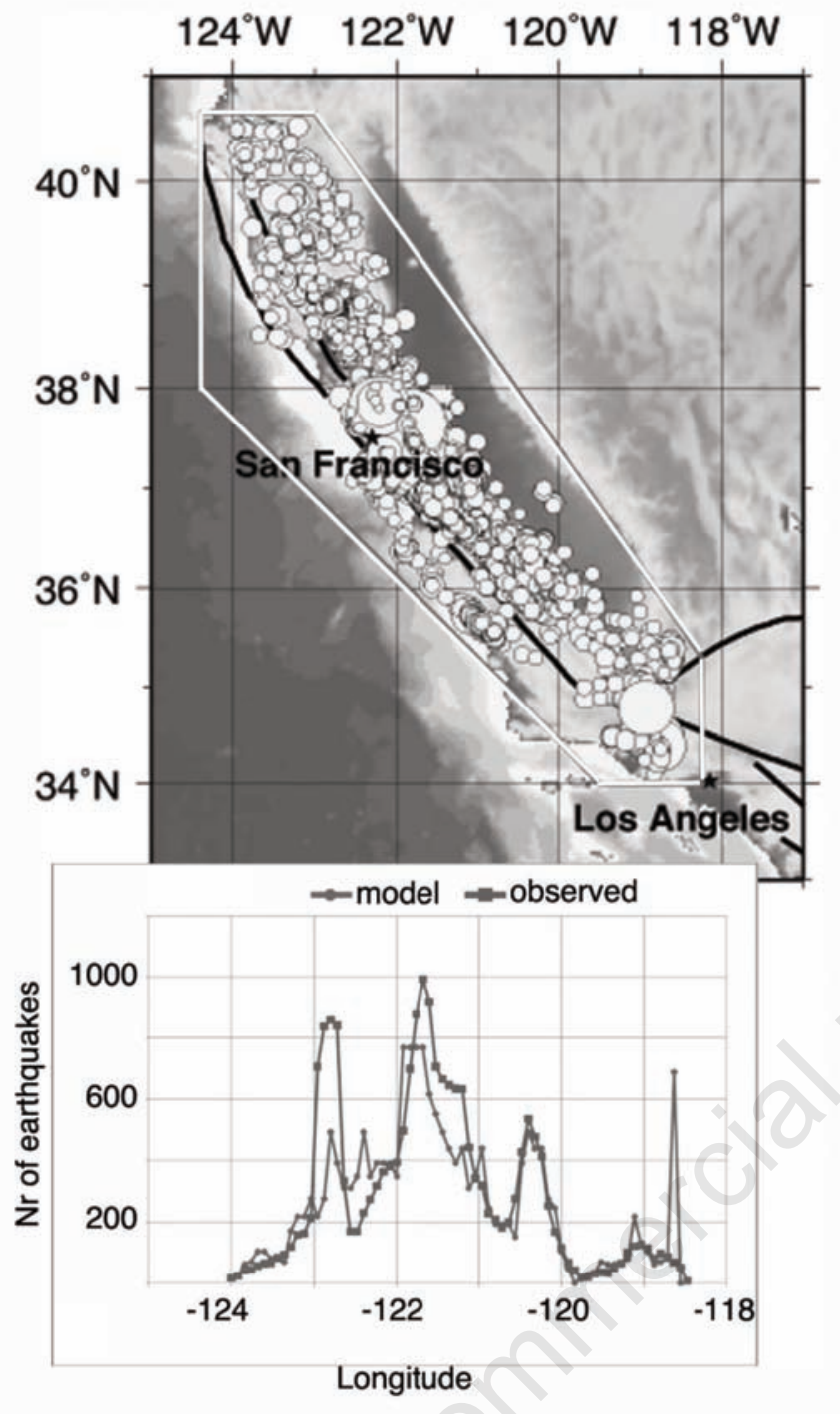

Figure 8. A map of SAFZ with modeled (circles) and observed (squares) earthquake frequencies against corresponding longitudes. White circles in the map show the earthquakes used in the calculations. The solid white polygon is the area we defined to extract seismicity.

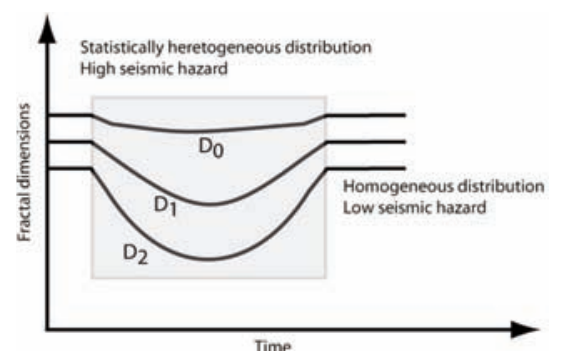

Figure 9. A sketch of proposed temporal fractal pattern. The shaded box indicates higher seismic hazard period. of the stress transfer model of Smalley et al. ${ }^{19}$ However, consideration of the temporal extent of heterogeneous behavior reduces relevance of fractal pattern. Fractal dimension decreases reported by Sukmono et al. ${ }^{14}$ and Lu et al. ${ }^{15}$ are further under-gridded by our findings (Figure 9). Spatial b-value distribution results are completely coherent with those previously established. ${ }^{11,12}$ Transitions between normal to higher stress states are characterized by larger earthquakes. After large shocks, stress and consequently b-values drop and fractal dimensions increase. High seismic hazard areas are well constrained by fractal dimensions, as further confirmed by elevated fractal dimensions during statistically homogeneous time periods.
Consistency between observations and modeling results strengthen their relevance to seismic hazard assessment. Anomalously high values of observed and modeled earthquake occurrence rate between $30.85^{\circ}-31.50^{\circ} \mathrm{E}$ longitudes may reflect an asperity zone, as suggested before in various works. ${ }^{27-30}$ Lower predicted values for seismicity may be due to incomplete elimination of aftershocks (Figure 7). Over and under estimation of observed earthquakes on the SAFZ occur east at approximately $120.5^{\circ} \mathrm{W}$ where strike changes abruptly, and approximately $122.5^{\circ} \mathrm{W}$ as a result of bifurcation (Figure 8). Inaccurate estimates may also arise from strength values held constant in the model, inducing a repeated characteristic pattern. Future studies could incorporate spatial fractal distribution to compensate for these artifacts. Assuming micro-earthquakes are symptomatic of larger earthquakes on stickslip fault zones, our model may provide valuable estimates of seismic hazard. We presume fractal spatio-temporal distribution of seismicity. Because fractals and chaos theory contain the concept of scale-invariant behavior, broad scale changes may be evidenced within smaller scales, which simultaneously define the larger picture. Any examination of such a chicken-egg phenomenon requires both conjunctive and separative analysis. Further research could incorporate different tectonic settings and better constraining scale-system interactions, thus contributing to a more complete comprehension of seismic hazard Moreover, 2D spatial distribution of fractal dimensions (Figure 3) may lead to more robust results. However, extensive tests are required to prove this hypothesis. Therefore, we prefer to limit our research to 1D spatio-temporal distribution.

\section{Conclusions}

Here, we argue that use of the renormalization group method in conjunction with fractal analysis of micro-seismicity may provide valuable insights into estimation of seismic hazard estimation. According to our results, the proposed model can be used to predict microearthquake occurrence for strike-slip faults with stick-slip behavior, assuming an increase in the frequency of micro-earthquakes is an indication of larger shock. We further propose that seismically active regions show a temporal b-value pattern: i) oscillating b-values; ii) exponential increase associated with increased seismic hazard (associated by decrease in fractal dimensions); and iii) stepwise decrease. 
of the earthquake frequency distribution. Geophys J R Astr Soc 1973;31:341-59.

12. Scholz CH. The frequency-magnitude relation of micro fracturing in rock and its relation to earthquakes. Bull Seism Soc Am 1968;58:399-415.

13. Legrand D. Fractal dimensions of small, intermediate and large earthquakes. Bull Seism Soc Am 2002;92:3318-20.

2. Grassberger P, Procaccia L. Measuring the strangeness of strange attractors. Physica 1983;9D:189-208.

3. Sarraille J, Difalco P. Computer program for estimation of fractal dimension. 1992. Available from: http://tori.postech.ac.kr/ softwares/

4. Liebovitch LS, Toth T. A fast algorithm to determine fractal dimensions by box counting. Phys Lett A 1989;141:386-90.

5. Gutenberg B, Richter C. Seismicity of the earth and associated phenomenon. 2nd ed. Princeton: Princeton University Press; 1954.

6. Aki K. Probabilistic synthesis of precursory phenomena, In: DW Simpson, PG Richards (eds.) Earthquake prediction an international review. Washington DC: Am Geophys Union; 1981. pp. 556-574.

7. Frohlich C, Davis SD. Teleseismic b values; or, much ado about 1.0. J Geophys Res 1993;98:631-44.

8. Turcotte DL. Fractals and chaos in geology and geophysics. 2nd ed. New York: Cambridge University Press; 1997.

9. Singh H, Bhattacharya PM, Chadha RK. Seismicity in the Koyna-Warna reservoir site in Western India: fractal and b-value mapping. Bull Seism Soc Am 2008;98:47682.

10. Mogi K. Magnitude-frequency relation for elastic shocks accompanying fractures of various material sand some related problems in earthquakes. Bull Earthquake Res Inst Tokyo Univ 1962;40:831-53.

11. Wyss M. Towards a physical understanding
14. Sukmono S, Zen MT, Hendrajaya L, et al. Fractal pattern of the Sumatra Fault seismicity and its possible application to earthquake prediction. Bull Seism Soc Am 1997;87:1685-90.

15. Lu C, Mai YW, Xie H. A sudden drop of fractal dimension: a likely precursor of catastrophic failure in disordered media. Philos Magazine Lett 2005;85:33-40.

16. Nakaya S. Fractal properties of seismicity in regions affected by large, shallow earthquakes in western Japan: implications for fault formation processes based on a binary fractal fracture network model. J Geophys Res 2005;110:B01310.

17. Wang JH. Studies of the frequency-magnitude relation of earthquakes based on a one-dimensional dynamical lattice model. Proc Natl Sci Counc ROC(A) 1999;23:16980.

18. Caneva A, Smirnov V. Using the fractal dimension of earthquake distribution sand slope of the recurrence curve to forecast earthquakes in Colombia. Earth Sci Res J 2004;8:3-9.

19. Smalley RF, Turcotte DL, Sola SA. A renormalization group approach to the stick-slip behavior of faults. J Geophys Res 1985; 90:1884-900.

20. Şaroğlu F, Emre Ö, Boray A. Türkiye'nin diri fayları ve depremsellikleri. MTA Raporu 1987;8174:1-394.

21. Barka A. The North Anatolian fault zone. Anna Tectonic 1992;6:164-95.
22. Le Pichon X, Şengör AMC, Demirbağ E, et al. The active Main Marmara fault. Earth Planet Sci Lett 2001;192:543-60.

23. Wessel P, Smith WHF. New, improved version of the generic mapping tools released. EOS Trans Am Geophys Union 1998;79:579.

24. Utsu T. Representation and analysis of the earthquake size distribution: a historical review and some new approaches. Pure Appl Geophys 1999;155:509-35.

25. Scholz CH. Earthquakes and faulting: Selforganized critical phenomena with a characteristic dimension. In: T Riste, D Sherrington (eds.) Spontaneous Formation of Space Time Structure and Criticality. Norwell Mass: Kluwer/Academic Publications;1991. pp. 41-56.

26. Rundle JB, Turcotte DL, Shcherbakov WK, Sammis C. Statistical physics approach to understanding the multiscale dynamics of earthquake fault systems. Rev Geophys 2003;41:1019.

27. Kaya T, Tank SB, Tuncer MK, et al. Asperity along the North Anatolian Fault imaged by magnetotellurics at Duzce, Turkey. Earth Planets Space 2009;61:871-84.

28. Pucci SS, Pantosti D, Barchi MR, Palyvos N. A complex seismogenic shear zone: The Duzce segment of north Anatolian fault (Turkey). Earth Planet Sci Lett 2007;262: 185-203.

29. Tank SB, Honkura Y, Ogawa Y, et al. Magnetotelluric imaging of the fault rupture area of the 1999 Izmit (Turkey) earthquake. Phys Earth Planet Inter 2005;150: 213-25.

30. Birgoren G, Sekiguchi H, Irikura K. Rupture model of the 1999, Duzce, Turkey, earthquake deduced from high and low frequency strong motion data. Geophys Res Lett 2004;31:L05610. 